\title{
Synthesis, characterization, biological activity and equilibrium studies of cadmium(II) with 2,6-diaminopyridine and various bio-relevant ligands
}

\author{
Azza Abdelwahab Shoukry a,b,* and Saedah Rwede Al-Mhayawi a \\ a Department of Chemistry, Faculty of Science for Girls, King Abdulaziz University, 50918 Jeddah, 21533 Kingdom of Saudi Arabia \\ b Department of Chemistry, Faculty of Science, Cairo University, 12613 Giza, Egypt \\ *Corresponding author at: Department of Chemistry, Faculty of Science, Cairo University, 12613 Giza, Egypt. \\ Tel.: +2.02.01005678891; fax: +2.02.25727213. E-mail address: azzashoukry@hotmail.com (A.A. Shoukry).
}

\section{ARTICLE INFORMATION}

Received: 18 April 2013

Accepted: 29 May 2013

Online: 30 September 2013

\section{KEYWORDS}

Speciation

Effect of solvent

Bioactive ligands

Stability constant

2,6-Diaminopyridine

Antimicrobial activity

\begin{abstract}
The complexing properties of 2,6-diaminopyridine (DAP) with cadmium(II) were investigated via measuring $\mathrm{pH}$ (i.e., $\mathrm{pH}$-metrically). Binary and ternary complexes of Cd(II) involving DAP and various biologically relevant ligands are investigated. The ligands used (L) were amino acids, dicarboxylic acids, amides and DNA unit constituents. The ternary complexes are formed by simultaneous reactions. The results showed the formation of Cd(DAP)(L) complexes with amino acids and dicarboxylic acids. Amides form both $\mathrm{Cd}(\mathrm{DAP})(\mathrm{L})$ complex and the corresponding deprotonated amide species $\mathrm{Cd}(\mathrm{DAP})\left(\mathrm{LH}_{-1}\right)$. The concentration distributions of the various complex species formed in solution were also evaluated as a function of $\mathrm{pH}$. The effect of dioxane as a solvent on the protonation constant of DAP and the formation constants of Cd(II)-DAP complexes were discussed. The solid complexes $[\mathrm{Cd}(\mathrm{DAP}) \mathrm{L})]$ where $\mathrm{L}=$ methionine and glycine, were isolated and characterized. The isolated solid complexes have also been screened for their antimicrobial activities against some selected bacteria and fungi. The activity data show that the complexes are found to have antibacterial and antifungal activity.
\end{abstract}

\section{Introduction}

The interest in coordination chemistry is increasing continuously with the synthesis and characterization of large number of transition metal complexes with heterocyclic ligands containing nitrogen, oxygen and sulfur donors. Studies of such ligands are relevant to medicine since they bear potential properties as chelators for the removal of toxic metals from the body. The great majority of the work of biological chemists is concerned with the coordination chemistry of essential metal ions in living organisms, and the examination of aspects of the interactions of these essential metal ions with the rest of the enzymes of the cells in which they are found. The toxic effects of cadmium in the form of $\mathrm{Cd}(\mathrm{II})$ are well documented. $\mathrm{Cd}(\mathrm{II})$ has been found to induce various pathological conditions, some of which may be fatal. Other conditions include cardiovascular diseases, hypertension and cancer [1]. The toxicology of cadmium (II) was noted to be governed by its interaction with an abundance of certain potential ligands in biological systems [2-6]. For example, in animals, Cd(II) accumulates mainly in the liver and kidney, where it is largely bound to thionine, a sulfurrich protein [7-9]. In red blood cells, Cd(II) is complexed by glutathione and hemoglobin [10]. The goal of chelating agent's treatment of metal intoxication is to transform a toxic metal bound to a constituent (usually a protein) of a living organism into a less toxic metal chelate which is readily excreted.

In discussing chelating agents design, it was reported that stability constant has long been recognized as a key factor in the determination of the ability of chelating agent to remove the metal from living organism [11].

2,6-Diaminopyridine is an example of an $\mathrm{N}$-donor ligand which combines the properties of both an $N$-heterocyclic and a primary aromatic amine and therefore, capable of forming stable complexes with $3 \mathrm{~d}$ transition metal ions including $\mathrm{Cd}(\mathrm{II})$. Cd(DAP $)^{2+}$ complex and the corresponding ternary complexes formed with different bio-relevant ligands as with amino acids, amides or DNA constituents may be considered as models in studying metalloenzyme-substrate interactions. With this in mind and in continuation of our research work directed to study binary and ternary complex formation equilibria with biologically active ligands [12-19] and in the course of the search for a new antidote for $\mathrm{Cd}(\mathrm{II})$, we report on the present investigation a quantitative study of the formation equilibria of binary and ternary complexes of Cd(II) with DAP and some bioactive ligands commonly exist in biological fluid. The second point of importance is the investigation of complex formation equilibria in solvents of lower polarity that represent some biological microenvironments, or simulate to some degree the situation in active site cavities. In spite that in vivo reactions take place in aqueous media, it has been reported that water is not an ideal model for in vivo reactions. In enzymes membranes and other biologically important media, the $\mathrm{p} K_{\mathrm{a}}$ values are far different from those in water, as these media tend to be lipophilic rather than hydrophilic. Therefore studies involving the calculation of the protonation constants in media other than water should provide some understanding of the chemistry of biorelevant ligands in biological systems. The effects of dioxane as a solvent on both the protonation constants and the formation constants of $\mathrm{Cd}(\mathrm{II})$ complexes with DAP are discussed.

The study also includes the synthesis and characterization of the ternary complexes of $\mathrm{Cd}(\mathrm{DAP})^{2+}$ with methionine and glycine known to have different coordination sites available for binding metal ions. The coordination sites of the ligands to 
$\mathrm{Cd}(\mathrm{DAP})^{2+}$ were discussed based on spectroscopic investigation. The isolated solid complexes were also screened for their antimicrobial activities using the disc diffusion method against some selected bacteria and fungi. The activity data show that the metal complexes are found to have antibacterial and antifungal activity.

\section{Experimental}

\subsection{Materials and reagents}

2,6-Diaminopyridine (DAP) was obtained from Sigma Chemical Company (USA). The amino acids: alanine, phenylalanine, valine, serine, $L$ - histamine. $\mathrm{HCl}$, methionine, together with the dicarboxylic acids: oxalic, malonic, succinic, adipic and cyclobutane 1,1-dicarboxylic acids (CBDCA) were provided by Sigma Chem. Co. as well as the amides: glycineamide and glutamine. The DNA constituents uracil, uridine, thymine, thymidine and inosine, were supplied by BDH-Biochemicals Ltd. $\mathrm{CdCl}_{2}$. was also obtained from Sigma Chem. Co. For stability constant determination, solution of $\left(0.01 \mathrm{~mol} \cdot \mathrm{dm}^{-3}\right)$ (DAP) was prepared in two equivalents $(0.02$ $\mathrm{mol} \cdot \mathrm{dm}^{-3}$ ) of $\mathrm{HNO}_{3}$ acid, freshly prepared solutions of DAP were used for all the measurements. $L$-Histamine. $\mathrm{HCl}$ was prepared in one equivalent $\left(0.01 \mathrm{~mol} \cdot \mathrm{dm}^{-3}\right)$ of $\mathrm{HNO}_{3}$ acid. Carbonate free $\mathrm{NaOH}$ (titrant) was prepared and standardized against potassium hydrogen phthalate solution.

\subsection{Synthesis of the ternary metal complexes}

The complexes were prepared by mixing clear solutions of DAP (272 $\mathrm{mg}, 2.5 \mathrm{mmol})$ and $\mathrm{CdCl}_{2}(281 \mathrm{mg}, 2.5 \mathrm{mmol})$ in distilled water $\left(10 \mathrm{~cm}^{3}\right)$ and the equivalent amount of the secondary ligands (188 mg, $2.5 \mathrm{mmol}$ for glycine) and (373 mg, $2.5 \mathrm{mmol}$ for methionine)) were then added to the above mixture with continuous stirring, followed by the addition of (266 mg, $2.5 \mathrm{mmol}$ ) of $\mathrm{Na}_{2} \mathrm{CO}_{3}$ to neutralize the protons released during complex formation. After complete addition of bicarbonate the reaction mixture was then refluxed for $2 \mathrm{~h}$ and kept overnight to insure complete reaction. The complexes were filtered, collected by and then washed several times with ethanol, followed by diethyl ether and dried under vacuum over silica gel. The yield ranged from $85-90 \%$. The dried complexes were subjected to elemental and spectroscopic analysis. The microchemical analysis of the separated solid complexes for $\mathrm{C}, \mathrm{H}$ and $\mathrm{N}$ was performed in the microanalytical center, Cairo University. The analyses were performed twice to check the accuracy of the analytical data. IR spectra were measured on 80486-PC FT-IR Shimadzu spectrophotometer using $\mathrm{KBr}$ pellets.

2,6-Diaminopyridine-methionine-cadmium(II) chloride, [Cd(DAP)(Meth)]Cl, (1): Color: Yellowish white. Yield: 85\%. M.p.: > $300{ }^{\circ} \mathrm{C}$. Anal. calcd. for $\mathrm{C}_{10} \mathrm{H}_{17} \mathrm{~N}_{4} \mathrm{O}_{2} \mathrm{SCdCl}$ : C, 29.64; $\mathrm{H}$, 4.23; N, 13.83. Found: C, 29.40; H, 5.00; N, $13.40 \%$

2,6-Diaminopyridine-glycine-cadmium(II)

[Cd(DAP)(Gly)]Cl, (2): Color: Light gray powder. Yielc M.p.: > $300{ }^{\circ} \mathrm{C}$. Anal. calcd. for $\mathrm{C}_{7} \mathrm{H}_{11} \mathrm{~N}_{4} \mathrm{O}_{2} \mathrm{CdCl}$ : C, 25.40; H, 3.35; $\mathrm{N}, 16.92$. Found: C, $25.60 ; \mathrm{H}, 4.20 ; \mathrm{N}, 16.50 \%$.

\subsection{Antibacterial activity}

The synthesized metal complexes were evaluated for their antibacterial activity and antifungal activities. The chosen strains were Staphylococcus aureus (as Gram-positive bacteria), Escherichia coli (as Gram-negative bacteria), Candida albicans and Aspergillus flavus as fungi. The analysis were performed using the paper disc diffusion method [12,20,21]. In this method the liquid medium containing the subcultures was autoclaved for $20 \mathrm{~min}$ at $121{ }^{\circ} \mathrm{C}$ before inoculation. The samples were then cultured in an incubator for $24 \mathrm{~h}$ at $36^{\circ} \mathrm{C}$ in case of bacteria and at $28{ }^{\circ} \mathrm{C}$ for $48 \mathrm{~h}$ in case of fungi. Muller
Hinton broth was used for preparing basal media for the bioassay of the organisms. Nutrient agar was poured onto a plate and allowed to solidify. The test compounds in $\left(5 \times 10^{-2}\right.$ mol.dm $\left.{ }^{-3}\right)$ DMSO solutions were added dropwise $(10 \mu \mathrm{L})$ to a 5 $\mathrm{mm}$ diameter filter paper disc placed at the centre of each agar plate. The plates were then kept at $5^{\circ} \mathrm{C}$ for $1 \mathrm{~h}$ then transferred to an incubator maintained at $36^{\circ} \mathrm{C}$. The width of the growth inhibition zone around the disc was measured after $24 \mathrm{~h}$ of incubation. Four replicates were made for each treatment and the recorded values are the mean average of replicates.

\subsection{Potentiometric procedure and measurements}

Potentiometric measurements were made using a Metrohm 686 Titroprocessor equipped with 665 dosimate. The titroprosessor and electrode were calibrated with standard buffer solutions prepared according to NBS specifications [21] at $\mathrm{T}=25.00 \pm 0.1{ }^{\circ} \mathrm{C}$, and $\mathrm{I}=0.1 \mathrm{~mol} . \mathrm{dm}^{-3}$, potassium hydrogen phthalate $(\mathrm{pH}=4.008)$ and a mixture of $\mathrm{KH}_{2} \mathrm{PO}_{4}$ and $\mathrm{Na}_{2} \mathrm{HPO}_{4}$ $(\mathrm{pH}=6.865)$. The $\mathrm{pH}$ meter readings were converted into hydrogen ion concentration by titrating a standard acid solution $\left(0.01 \mathrm{~mol}^{-\mathrm{dm}^{-3}}\right)$, the ionic strength of which was adjusted to 0.1 mol.dm ${ }^{3}$ with $\mathrm{NaNO}_{3}$, with standard base $(0.10$ $\mathrm{mol} / \mathrm{L})$ at $25{ }^{\circ} \mathrm{C}$. The $\mathrm{pH}$ is plotted against $\mathrm{p}[\mathrm{H}]$. The relationship $\mathrm{pH}-\mathrm{p}[\mathrm{H}]=0.05$ was observed. $\left[\mathrm{OH}^{-}\right]$value was calculated using a $\mathrm{pK}_{w}$ value of 13.997 [22]. All potentiometric titrations were carried out at $25 \pm 0.05^{\circ} \mathrm{C}$, in a double-walled glass cell of $50 \mathrm{~mL}$ capacity. The temperature of all solutions was maintained at $25 \pm 0.05{ }^{\circ} \mathrm{C}$ by circulation of thermostated water through the outer jacket of the cell. The solutions were stirred with a magnetic stirrer, and all titrations were performed in triplicate.

As is well known, pH-meters read $-\log _{10} a_{H^{+}}(\mathrm{pH})$ whereas the potentiometric method we used for the calculation of stability constants requires $-\log _{10}\left[\mathrm{H}^{+}\right](\mathrm{p}[\mathrm{H}])$. The $\mathrm{pH}$-meter readings (B) recorded in dioxane-water solutions was converted to hydrogen ion concentrations $\left[\mathrm{H}^{+}\right]$by using the widely used Van Uitert and Hass equation, Equation 1 [23]:

$$
-\log _{10}\left[\mathrm{H}^{+}\right]=B+\log _{10} U_{\mathrm{H}}
$$

where $\log _{10} U_{\mathrm{H}}$ is the correction factor for the solvent composition and ionic strength for which $B$ is determined. Values of $\mathrm{p} K_{\mathrm{w}}$ in dioxane-water mixtures were determined as described previously [24,25]. For this purpose, various amounts of standard $\mathrm{NaOH}$ solution were added to a solution containing $0.1 \mathrm{~mol} \cdot \mathrm{dm}^{-3} \mathrm{NaNO}_{3}$. The values of $\left[\mathrm{OH}^{-}\right]$were calculated from the amount of base added; $\left[\mathrm{H}^{+}\right]$was calculated from the $\mathrm{pH}$. The product of $\left[\mathrm{OH}^{-}\right]$and $\left[\mathrm{H}^{+}\right]$were used to calculate the $\mathrm{p} K_{\mathrm{w}}$ values described above. The mean values obtained in this way at $25{ }^{\circ} \mathrm{C}$ for $\log _{10}\left[\mathrm{H}^{+}\right]\left[\mathrm{OH}^{-}\right]$are $\mathrm{p} K_{\mathrm{w}}=$ $14.17,14.60,15.12$ and 15.49 for $12.5,25,37.5$ and $50 \%$ dioxane-water solutions respectively. The values were found to be consistent with literature data [26,27].

The protonation constants of the ligands, in the protonated form were determined potentiometrically by titrating the ligand $\left(40 \mathrm{~cm}^{3}\right)$ solution $\left(1.25 \times 10^{-3} \mathrm{~mol} . \mathrm{dm}^{-3}\right)$ of constant ionic strength $0.1 \mathrm{~mol} \mathrm{dm}^{-3}$, (adjusted with $\mathrm{NaNO}_{3}$ ). The stability constant of the Cd(DAP) complex was determined by titrating $40 \mathrm{~cm}^{3}$ of a solution mixture of $\mathrm{Cd}(\mathrm{II})\left(1.25 \times 10^{-3} \mathrm{~mol}^{-\mathrm{dm}^{-3}}\right)$, DAP ligand $\left(2.5 \times 10^{-3} \mathrm{~mol} \mathrm{dm}^{-3}\right)$ and $\mathrm{NaNO}_{3}\left(0.1 \mathrm{~mol}^{-\mathrm{dm}^{-3}}\right)$. The conditions of measurements of the ternary complexes were the same as for the binary ones, but the solutions contained equivalent amounts of DAP, Cd(II) and other ligands (L) in concentration ratio 1:1:1 for amino acids, dicarboxylic acids, and peptides and 1:1:2 for the DNA constituents. All titrations were performed in a purified $\mathrm{N}_{2}$ atmosphere using aqueous $0.05 \mathrm{mol.dm}^{-3} \mathrm{NaOH}$ as titrant.

The general four component equilibrium can be written as follows (charges are omitted for simplicity) 
$\mathrm{l}(\mathrm{Cd})+\mathrm{p}(\mathrm{DAP})+\mathrm{q}(\mathrm{L})+\mathrm{r}(\mathrm{H}) \rightleftharpoons(\mathrm{Cd}) \mathrm{l}+(\mathrm{DAP}) \mathrm{p}(\mathrm{L}) \mathrm{q}(\mathrm{H}) \mathrm{r}$

$\beta_{\text {lpqr }}=\frac{\left[(\mathrm{Cd})_{1}(\mathrm{DAP})_{\mathrm{p}}(\mathrm{L})_{\mathrm{q}}(\mathrm{H})_{\mathrm{r}}\right]}{[\mathrm{Cd}]^{1}[\mathrm{DAP}]^{\mathrm{p}}[\mathrm{L}]^{\mathrm{q}}[\mathrm{H}]^{\mathrm{r}}}$

\subsection{Data processing}

The calculations were obtained from $c a .100$ data points in each titration using the least-squares computer program [28] MINIQUAD-75. The stoichiometries and stability constants of the complexes formed were determined by trying various possible composition models. The model selected gave the best statistical fit and was chemically consistent with the titration data without showing any systematic bias in residuals [28]. The fitted model was tested by comparing the experimental titration data point and the theoretical (simulated) curve calculated from the values of the acid dissociation constants of the ligand and the formation constant of the corresponding complex, as given in Table 1 . The complexation equilibria were elucidated from the concentration distribution curves obtained with the program SPECIES [29] under the experimental condition used.

\section{Results and discussion}

The proton dissociation constants of the ligands and the formation constants of their binary complexes were determined under the same experimental conditions of ionic strength and temperature used to study the ternary complexes. The results obtained are in good agreement with the literature data [11].

\subsection{Acid-base equilibria of DAP}

In order to calculate the stability constants of metal complexes, the acid dissociation constant of the ligand was first determined. The most accepted model for analysis of the potentiometric data of (DAP) yields two $\mathrm{pKa}$ values 6.83 and 2.89 corresponding to amino group and the protonated pyridine ring respectively (Table 1) [30].

\subsection{Formation equilibria of binary Cd(II)-DAP complexes}

The stability constants of metal complexes were measured potentiometrically by knowing the ligand $\mathrm{p} K_{a}$. DAP was titrated in presence and in absence of Cd(II) ion. The Cd(II)-DAP titration curve was lowered from that of DAP curve (Figure 1). This indicates a complex formation associated with the release of hydrogen ion. The titration data were evaluated by assuming all feasible models. The equilibrium pattern was selected by successive attempts according to the best agreement between observed and calculated data, the standard deviation of the formation constant and the chemical significance of the species proposed. The accepted model is found to be consistent with the formation of the species with the stoichiometries (110) and (120). This model was tested by comparing the experimental titration data points and the theoretical curve calculated from the acid dissociation constant values of DAP and formation constant of the Cd(DAP) ${ }^{2+}$ complexes. The good fit between the experimental and theoretical curves is an indication of the validity of the complex formation model. 2,6-Diaminopyridine is an example of an $\mathrm{N}$ - donor ligand which combines the properties of both an N-heterocyclic and a primary aromatic amine. Based on the resulting data the coordination of DAP to $\mathrm{Cd}(\mathrm{II})$ ion is suggested most likely to occur through the two amino groups forming a stable 6-membered chelate ring as shown in Scheme 1. The corresponding stability constant values are $\log _{10} K_{1}=6.56$ and $\log _{10} K_{2}=5.22$. These results show that the successive stability constants of the binary complexes decrease in accordance with statistical expectation.
The $\left(\log _{10} K_{1}-\log _{10} K_{2}\right)$ values are usually positive, since the coordination sites of the metal ions are more freely available for binding of the first ligand than the second.

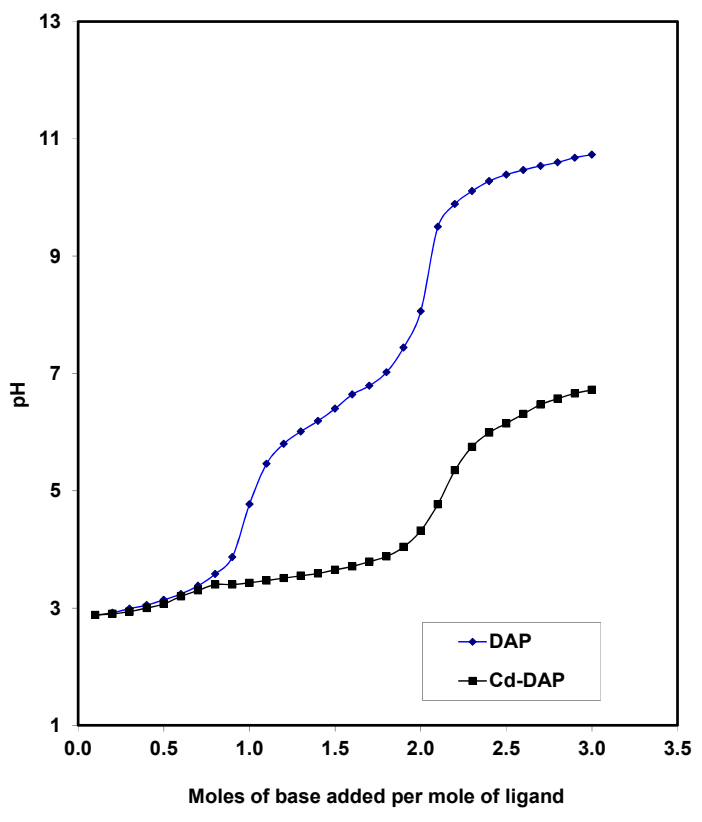

Figure 1. Potentiometric titration curves of the Cd-DAP system.
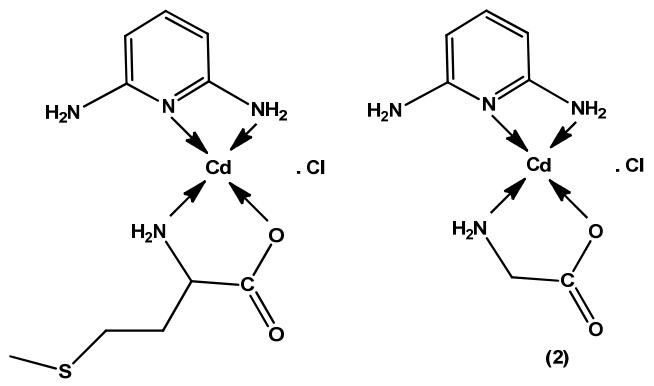

(2)

Scheme 1

\subsection{Ternary complex formation equilibria}

The ternary complex formation equilibria may proceed through either step-wise or simultaneous mechanism [21] depending on the chelating ability of the two ligands, DAP and other ligands (L), to $\mathrm{Cd}(\mathrm{II})$. The formation constants of the binary 1:1 Cd(II)-L complexes were determined and the values are given in Table 1 . The results show that the formation constants of the binary cadmium(II) complexes with DAP and the studied ligands as amino acid, peptides or DNA units are nearly of the same order of magnitude. Consequently, the ligation of DAP and other selected ligands will occur simultaneously according to the following equilibrium (4).

$\mathrm{Cd}+\mathrm{DAP}+\mathrm{L} \rightleftharpoons \mathrm{Cd}(\mathrm{DAP})(\mathrm{L})$

The overall formation constants values expressed as log $B_{1110}$ and given in Table 1 were calculated considering the acid dissociation constants of the ligands and formation constants of the binary complexes as known quantities. Figure 2 presents the potentiometric titration curve for the Cd-DAP-alanine system according to the simultaneous mechanism. 
Table 1. Stability constants of the ternary species in the Cd(II)-DAP-amino acids, peptides or dibasic acid systems and proton-association constants and their binary stability constants.

\begin{tabular}{|c|c|c|c|c|c|c|}
\hline System & 1 & $\mathbf{p}$ & $q$ & $\mathbf{r}^{\mathbf{a}}$ & $\log \beta^{b}$ & $\mathrm{~S} \mathrm{c}^{\mathrm{c}}$ \\
\hline \multirow{2}{*}{$\mathrm{Cd}\left(\mathrm{H}_{2} \mathrm{O}\right)_{6}{ }^{2+}$} & 1 & 0 & 0 & -1 & $-9.11(0.01)$ & $2.6 \times 10^{-8}$ \\
\hline & 1 & 0 & 0 & -2 & $-18.52(0.02)$ & \\
\hline \multirow[t]{4}{*}{$\overline{\mathrm{DAP}}$} & 0 & 1 & 0 & 1 & $6.83(0.01)$ & $2.4 \times 10^{-7}$ \\
\hline & 0 & 1 & 0 & 2 & $9.72(0.02)$ & \\
\hline & 1 & 1 & 0 & 0 & $6.56(0.02)$ & $3.6 \times 10^{-7}$ \\
\hline & 1 & 2 & 0 & 0 & $11.78(0.04)$ & \\
\hline \multirow[t]{4}{*}{ Alanine } & 0 & 0 & 1 & 1 & $9.59(0.01)$ & $1.6 \times 10^{-7}$ \\
\hline & 1 & 0 & 1 & 0 & $4.41(0.05)$ & \\
\hline & 1 & 0 & 2 & 0 & $7.77(0.07)$ & $3.0 \times 10^{-7}$ \\
\hline & 1 & 1 & 1 & 0 & $10.17(0.03)$ & $1.3 \times 10^{-7}$ \\
\hline \multirow[t]{6}{*}{ Phenylalanine } & 0 & 0 & 1 & 1 & $9.12(0.01)$ & $2.0 \times 10^{-8}$ \\
\hline & 0 & 0 & 1 & 2 & $11.01(0.03)$ & \\
\hline & 1 & 0 & 1 & 0 & $4.42(0.01)$ & $4.3 \times 10^{-8}$ \\
\hline & 1 & 0 & 2 & 0 & $7.37(0.01)$ & \\
\hline & 1 & 0 & 3 & 0 & $11.63(0.05)$ & \\
\hline & 1 & 1 & 1 & 0 & $11.28(0.03)$ & $5.5 \times 10^{-7}$ \\
\hline \multirow[t]{5}{*}{ Methionine } & 0 & 0 & 1 & 1 & $9.12(0.02)$ & $1.1 \times 10^{-8}$ \\
\hline & 1 & 0 & 1 & 0 & $4.35(0.03)$ & \\
\hline & 1 & 0 & 2 & 0 & $7.55(0.02)$ & \\
\hline & 1 & 0 & 3 & 0 & $11.83(0.03)$ & $1.3 \times 10^{-8}$ \\
\hline & 1 & 1 & 1 & 0 & $11.24(0.03)$ & $1.4 \times 10^{-7}$ \\
\hline \multirow[t]{5}{*}{$\overline{\text { Serine }}$} & 0 & 0 & 1 & 1 & $8.77(0.01)$ & $3.2 \times 10^{-8}$ \\
\hline & 1 & 0 & 1 & 0 & $3.97(0.02)$ & \\
\hline & 1 & 0 & 2 & 0 & $7.17(0.01)$ & \\
\hline & 1 & 0 & 3 & 0 & $10.36)(0.01)$ & $8.3 \times 10^{-9}$ \\
\hline & 1 & 1 & 1 & 0 & $11.37(0.03)$ & $8.4 \times 10^{-7}$ \\
\hline \multirow[t]{5}{*}{ Valine } & 0 & 0 & 1 & 1 & $9.57(0.01)$ & $7.0 \times 10^{-8}$ \\
\hline & 0 & 0 & 1 & 2 & $11.71(0.02)$ & \\
\hline & 1 & 0 & 1 & 0 & $4.14(0.01)$ & $3.1 \times 10^{-8}$ \\
\hline & 1 & 0 & 2 & 0 & $7.15(0.02)$ & \\
\hline & 1 & 1 & 1 & 0 & $11.96(0.05)$ & $4.2 \times 10^{-7}$ \\
\hline \multirow[t]{7}{*}{$\overline{L \text {-Histamine }}$} & 0 & 0 & 1 & 1 & $9.85(0.01)$ & $2.4 \times 10^{-8}$ \\
\hline & 0 & 0 & 1 & 2 & $16.07(0.01)$ & \\
\hline & 1 & 0 & 1 & 0 & $7.24(0.01)$ & $2.8 \times 10^{-8}$ \\
\hline & 1 & 0 & 2 & 0 & $11.19(0.03)$ & \\
\hline & 1 & 0 & 2 & 1 & $19.68(0.01)$ & \\
\hline & 1 & 1 & 1 & 0 & $15.86(0.04)$ & $3.4 \times 10^{-9}$ \\
\hline & 1 & 1 & 1 & 1 & $21.71(0.02)$ & \\
\hline Glycinamide & 0 & 0 & 1 & 1 & $7.88(0.01)$ & $4.6 \times 10^{-8}$ \\
\hline & 1 & 0 & 1 & 0 & $2.65(0.04)$ & $6.4 \times 10^{-7}$ \\
\hline & 1 & 0 & 2 & 0 & $4.68(0.02)$ & \\
\hline & 1 & 1 & 1 & 0 & $10.97(0.05)$ & $1.1 \times 10^{-8}$ \\
\hline & 1 & 1 & 1 & -1 & $3.56(0.01)$ & \\
\hline Glutamine & 0 & 0 & 1 & 1 & $7.96(0.01)$ & $1.1 \times 10^{-8}$ \\
\hline & 1 & 0 & 1 & 0 & $3.19(0.01)$ & $6.4 \times 10^{-7}$ \\
\hline & 1 & 0 & 2 & 0 & $6.35(0.02)$ & \\
\hline & 1 & 1 & 1 & 0 & $11.43(0.03)$ & $4.2 \times 10^{-7}$ \\
\hline & 1 & 1 & 1 & -1 & $2.70(0.05)$ & \\
\hline$\overline{\text { Oxalic acid }}$ & 0 & 0 & 1 & 1 & $3.93(0.01)$ & $1.3 \times 10^{-9}$ \\
\hline & 0 & 0 & 1 & 2 & $5.66(0.01)$ & \\
\hline & 1 & 0 & 1 & 0 & $6.68(0.05)$ & $3.7 \times 10^{-7}$ \\
\hline & 1 & 0 & 2 & 0 & $11.27(0.08)$ & \\
\hline & 1 & 1 & 1 & 0 & $15.80(0.04)$ & $3.5 \times 10^{-9}$ \\
\hline & 1 & 1 & 1 & 1 & $18.29(0.02)$ & \\
\hline 1,1-CBDCA & 0 & 0 & 1 & 1 & $5.68(0.01)$ & $5.4 \times 10^{-8}$ \\
\hline & 0 & 0 & 1 & 2 & $8.80(0.02)$ & \\
\hline & 1 & 0 & 1 & 0 & $6.54(0.03)$ & $1.7 \times 10^{-7}$ \\
\hline & 1 & 0 & 2 & 0 & $9.19(0.09)$ & \\
\hline & 1 & 0 & 1 & 1 & $10.27(0.04)$ & \\
\hline & 1 & 1 & 1 & 0 & $14.10(0.06)$ & $7.9 \times 10^{-8}$ \\
\hline & 1 & 1 & 1 & 1 & $17.81(0.01)$ & \\
\hline Malonic acid & 0 & 0 & 1 & 1 & $5.21(0.01)$ & $2.0 \times 10^{-9}$ \\
\hline & 0 & 0 & 1 & 2 & $7.61(0.01)$ & \\
\hline & 1 & 0 & 1 & 0 & $5.02(0.05)$ & $3.3 \times 10^{-8}$ \\
\hline & 1 & 0 & 2 & 0 & $9.06(0.08)$ & \\
\hline & 1 & 0 & 1 & 1 & $9.92(0.09)$ & \\
\hline & 1 & 1 & 1 & 0 & $12.60(0.04)$ & $2.7 \times 10^{-7}$ \\
\hline & 1 & 1 & 1 & 1 & $17.46(0.05)$ & \\
\hline Succinic acid & 0 & 0 & 1 & 1 & $5.21(0.01)$ & $5.3 \times 10^{-10}$ \\
\hline & 0 & 0 & 1 & 2 & $9.26(0.01)$ & \\
\hline & 1 & 0 & 1 & 0 & $4.40(0.01)$ & $1.8 \times 10^{-9}$ \\
\hline & 1 & 0 & 2 & 0 & $7.42(0.03)$ & \\
\hline & 1 & 0 & 1 & 1 & $9.56(0.01)$ & \\
\hline & 1 & 1 & 1 & 0 & $11.64(0.02)$ & $1.4 \times 10^{-7}$ \\
\hline & 1 & 1 & 1 & 1 & $17.12(0.04)$ & \\
\hline
\end{tabular}


Table 1. (Continued).

\begin{tabular}{|c|c|c|c|c|c|c|}
\hline System & 1 & $p$ & $q$ & $\mathbf{r a}^{\mathbf{a}}$ & $\log \beta^{b}$ & $S^{c}$ \\
\hline \multirow{7}{*}{ Adipic acid } & 0 & 0 & 1 & 1 & $5.11(0.01)$ & $3.5 \times 10^{-9}$ \\
\hline & 0 & 0 & 1 & 2 & $9.35(0.01)$ & \\
\hline & 1 & 0 & 1 & 0 & $4.18(0.08)$ & $2.9 \times 10^{-8}$ \\
\hline & 1 & 0 & 2 & 0 & $7.93(0.07)$ & \\
\hline & 1 & 0 & 1 & 1 & $8.96(0.06)$ & \\
\hline & 1 & 1 & 1 & 0 & $10.40(0.01)$ & $1.2 \times 10^{-8}$ \\
\hline & 1 & 1 & 1 & 1 & $16.08(0.04)$ & \\
\hline \multirow[t]{4}{*}{$\overline{\text { Uracil }}$} & 0 & 0 & 1 & 1 & $9.28(0.02)$ & $3.5 \times 10^{-9}$ \\
\hline & 1 & 0 & 1 & 0 & $3.35(0.01)$ & \\
\hline & 1 & 0 & 2 & 0 & $6.99(0.02)$ & $2.9 \times 10^{-8}$ \\
\hline & 1 & 1 & 1 & 0 & $10.18(0.09)$ & \\
\hline \multirow[t]{4}{*}{ Uridine } & 0 & 0 & 1 & 1 & $9.01(0.02)$ & $3.5 \times 10^{-9}$ \\
\hline & 1 & 0 & 1 & 0 & $3.45(0.01)$ & \\
\hline & 1 & 0 & 2 & 0 & $7.19(0.02)$ & $2.9 \times 10^{-8}$ \\
\hline & 1 & 1 & 1 & 0 & $11.18(0.09)$ & \\
\hline \multirow[t]{4}{*}{ Thymine } & 0 & 0 & 1 & 1 & $9.58(0.02)$ & $3.5 \times 10^{-9}$ \\
\hline & 1 & 0 & 1 & 0 & $3.77(0.01)$ & \\
\hline & 1 & 0 & 2 & 0 & $7.26(0.03)$ & $2.9 \times 10^{-8}$ \\
\hline & 1 & 1 & 1 & 0 & $10.91(0.03)$ & $1.9 \times 10^{-7}$ \\
\hline \multirow[t]{4}{*}{ Thymidine } & 0 & 0 & 1 & 1 & $9.55(0.02)$ & $3.5 \times 10^{-9}$ \\
\hline & 1 & 0 & 1 & 0 & $3.60(0.01)$ & \\
\hline & 1 & 0 & 2 & 0 & $7.38(0.09)$ & $2.9 \times 10^{-8}$ \\
\hline & 1 & 1 & 1 & 0 & $11.88(0.02)$ & \\
\hline \multirow[t]{5}{*}{ Inosine } & 0 & 0 & 1 & 1 & $8.43(0.02)$ & $3.5 \times 10^{-9}$ \\
\hline & 1 & 0 & 1 & 0 & $3.87(0.01)$ & \\
\hline & 1 & 0 & 2 & 0 & $7.99(0.01)$ & $2.9 \times 10^{-8}$ \\
\hline & 1 & 1 & 1 & 0 & $11.62(0.03)$ & $1.9 \times 10^{-8}$ \\
\hline & 1 & 1 & 1 & 1 & $18.43(0.02)$ & \\
\hline
\end{tabular}

a $l, p, q$ and $r$ are the stoichiometric coefficients corresponding to CdII, DAP, other ligand and $\mathrm{H}^{+}$, respectively.

bStandard deviation are given in parentheses.

c Sum of square of residuals.

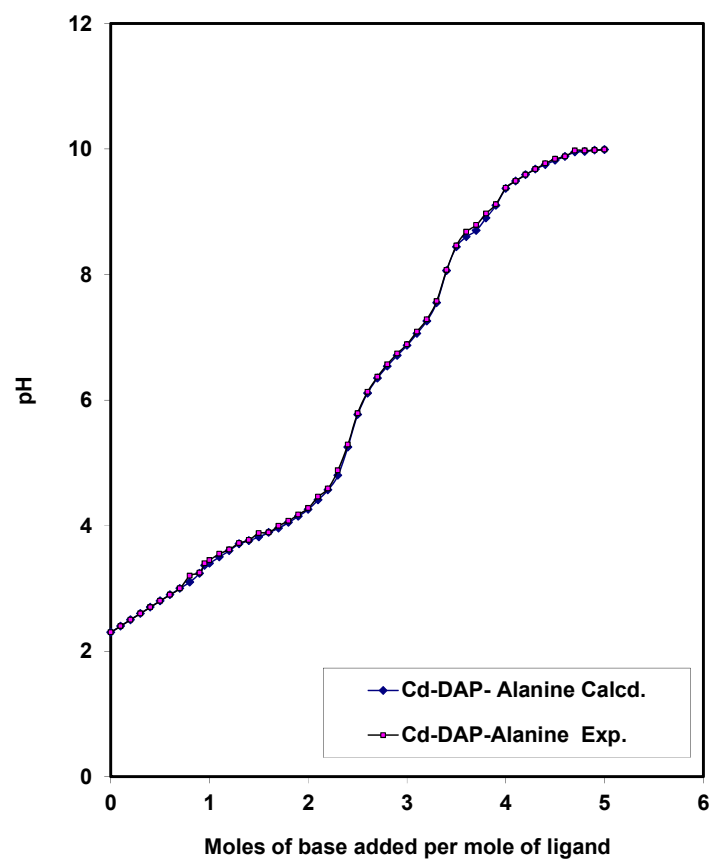

Figure 2. Experimental and calculated potentiometric titration curves for the Cd-DAP-Alanine system.

The stability constant of the ternary complex formed with Phenylalanine is higher than that of alanine, although the amino group of the phenylalanine is less basic than that of the alanine. This may be explained on the premise that the non coordinating aromatic side groups of phenylalanine can approach the aromatic moiety of DAP and exert a stacking interaction in the [Cd(DAP)Phenylalanine] complex, since the presence of an aromatic ring above the $\mathrm{Cd}(\mathrm{II})$ coordination plane is probably essential for preferential formation of ternary complexes. This will contribute to increase the stability of the formed complex.
The stability constant of the mixed-ligand complexes of serine and methionine are in fair agreement with those of the studied amino acids, taking the difference in the acid dissociation constants of the amino acids into consideration. This indicates that methionine and serine participate in mixedligand complex formation as substituted glycinate. Consequently, the thioether group in methionine and $\beta$ alcoholato-group in serine do not participate in complex formation, as previously reported for the copper(II) complexes $[11,31,32]$.

Histamine has two binding sites via imidazole and amino group. The stability constant values for the complexes formed with histamine are relatively higher than those of amino acids, which indicate the coordination through amino and imidazole groups. Histamine has been shown to form protonated complex species (1111). The acid dissociation constants of the protonated species are given by the following equation.

$$
p K_{C d(D A P) L}^{H}=\log _{10} K_{C d(D A P)(L)(H)}^{C d(D A P)}-\log _{10} K_{C d(D A P)(L)}^{C d(D A P)}
$$

The $\mathrm{p} K_{\mathrm{a}}$ value for the histamine complex is (5.85), being lower than that of the protonated amino group $\left(-\mathrm{NH}_{3}+\right.$ in the histamine ligand $\left(\mathrm{p} K_{\mathrm{a}}=9.85\right)$ but closer to that of the protonated imidazole $\left(\mathrm{pK}_{\mathrm{a}}=6.22\right)$, considering the increase in acidity due to complex formation. This reveals that the proton in the protonated complex would be located mainly on the imidazole.

The ionized amide residue of the amides, [-CONH-], behaves as an important ligating group. In the case of glutamine and glycinamide as examples of amides (HL), the complex species formed are [Cd(DAP)(L)] and [Cd(DPA, $\left.\left.\mathrm{LH}_{-1}\right)\right]$. The species $[\mathrm{Cd}(\mathrm{DAP})(\mathrm{L})]$ is formed by coordination through the amine and carbonyl groups. On increasing the $\mathrm{pH}$, the coordination sites should switch from carbonyl oxygen to amide nitrogen. The amide groups undergo deprotonation and the $\left[\mathrm{Cd}\left(\mathrm{DPA}, \mathrm{LH}_{-1}\right)\right]$ complexes species is formed. Such changes in coordination centers are now well documented $[33,34]$. The $\mathrm{p} K^{\mathrm{H}}$ values of the amide groups incorporated in complexes are calculated by the following Equation 6. 
Table 2. Tentative assignment of the important infrared bands of the synthesized ternary complexes.

\begin{tabular}{|c|c|c|c|c|c|c|c|}
\hline \multirow{2}{*}{$\begin{array}{l}\text { Complexes } \\
\text { Empirical formula }\end{array}$} & \multicolumn{7}{|c|}{ Assigned wavenumbers $\left(\mathrm{cm}^{-1}\right)$} \\
\hline & $v_{\text {coo (sym.) }}$ & $V_{\text {COO (asym.) }}$ & $\mathrm{NNH}_{\mathrm{NH}}$ & WN2 & $\nu \mathrm{C}=\mathrm{H}$ & $v_{\mathrm{Cd}-0}$ & $v_{\mathrm{Cd}-\mathrm{N}}$ \\
\hline [Cd(DAP)-Meth]Cl & 1310.5 & 1660.5 & 3142 & 3317 & 2786 & 450 & 267 \\
\hline [Cd(DAP)-Gly]Cl & 1391.3 & 1642.6 & 3137 & 3277 & 2646 & 440 & 580 \\
\hline
\end{tabular}

$\mathrm{p} K^{\mathrm{H}}=\log _{10} \beta_{1110}-\log _{10} \beta_{111-1}$

The calculated $\mathrm{p} K^{\mathrm{H}}$ values are 7.41 and 8.73 for glycinamide and glutamine, respectively. It is noteworthy that the $\mathrm{p} K^{\mathrm{H}}$ for the glycinamide complex is lower than the $\mathrm{p} K^{\mathrm{H}}$ of glutamine. This indicates that the more bulky substituent group on the amides may serve to hinder the structural change in going from protonated to deprotonated complexes. Moreover, the higher $\mathrm{p} K^{\mathrm{H}}$ of the glutamine complex, with respect to that of glycineamide could be attributed to the formation of a seven membered chelate ring, which would be more strained and less favored. The speciation diagram of glutamine complex, as a representative amide, is given in Figure 3 . The mixed ligand species [Cd([DAP)L] (1110) starts to form at $\mathrm{pH} \approx 4$ and with increasing of $\mathrm{pH}$, its concentration increases reaching the maximum of $79 \%$ at $\mathrm{pH}=5.8$. Further increase of $\mathrm{pH}$ is accompanied by a decrease in 1110 complex concentration and an increase in [Cd(DAP)LH-1] (111-1) complex formation.

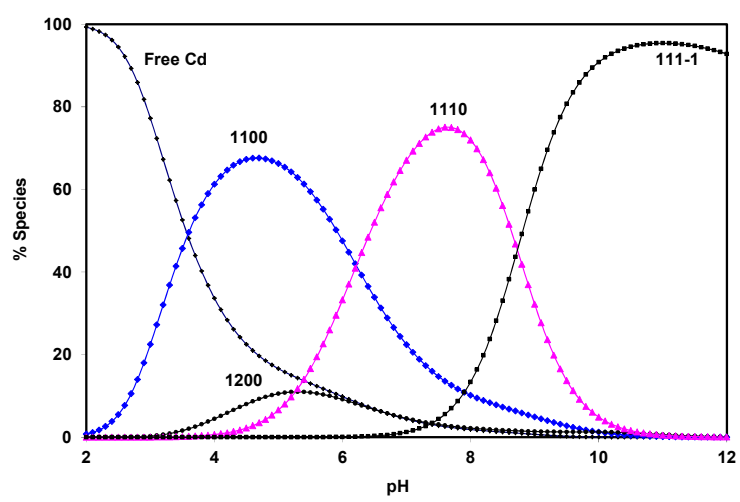

Figure 3. Concentration distribution of various species as a function of $\mathrm{pH}$ for the [Cd(DAP)-Glutamine] system at a concentration of $1.25 \mathrm{mmol}^{-\mathrm{dm}^{-3}}$ for Cd, DAP and Glutamine.

The pyrimidinic species (uridine, uracil, thymine and thymidine) have a dissociable proton at N(3). The potentiometric data of the mixed-ligand complexes involving uracil, and thymine are fitted assuming that these ligands are bound in the deprotonated form through N3 atom as previously reported [35]. The thymine complex is more stable than that of uracil most probably due to the higher basicity of the N(3) site of thymine resulting from the inductive effect of the extra electron-donating methyl group.

The purinic species inosine have two metal ion binding centers $\mathrm{N}_{1}$ and $\mathrm{N}_{7}$ nitrogen's. Previous studies have revealed that $\mathrm{N} 1$ is the binding site in basic medium [12,36,37]. Therefore, in the $\mathrm{pH}$ range from 7-9, inosine may bind through the $\mathrm{N} 1$ atom in the mixed ligand complex formation. The results showed that inosine form the complexes 1110 and 1111. The species 1111 is formed in the acidic $\mathrm{pH}$ region and it corresponds to the $\mathrm{N}_{7}$ coordinated complex, while $\mathrm{N}_{1}$ nitrogen is in protonated form. The $\mathrm{p} K_{\mathrm{a}}$ of the protonated form $\left(\log \beta_{1111}\right.$ - $\left.\log \beta_{1110}\right)$ amounts to 6.81 . The speciation of the inosine complex is presented in Figure 4, where the species distribution of the complexes is plotted as a function of $\mathrm{pH}$. Figure 4, indicates that the 1111 complex is formed in the acidic $\mathrm{pH}$ range, which corresponds to the $\mathrm{N}(7)$ coordinated species, while $\mathrm{N}(1)$ is still protonated. Increasing of $\mathrm{pH}$ is accompanied by a decrease in the 1111 complex concentration and an increase in that of [Cd(DPA)Inosine] (1110), reaching a maximum concentration of $95 \%$ at $\mathrm{pH}=9.5$

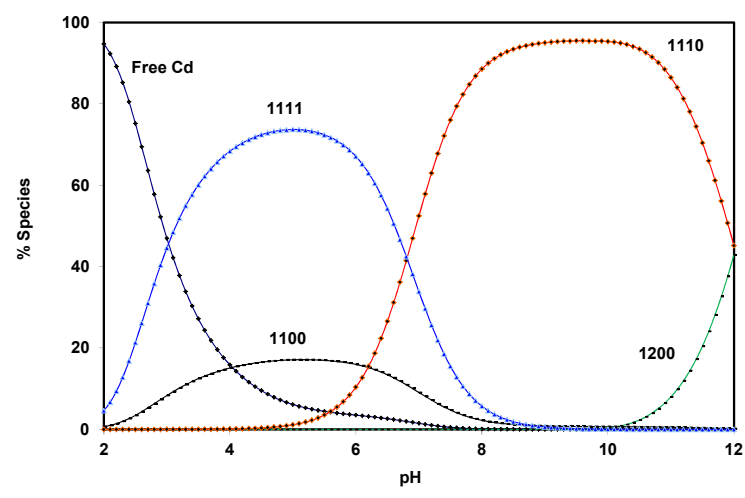

Figure 4. Concentration distribution of various species as a function of $\mathrm{pH}$ for the [Cd(DAP)-Inosine] system at a concentration of $1.25 \mathrm{mmol}^{-\mathrm{dm}^{-3}}$ for Cd(DAP) and $2.5 \mathrm{mmol}^{-\mathrm{dm}^{-3}}$ for Inosine.

\subsection{Characterization of solid complexes}

All complexes are stable in air allowing physical measurements. IR spectra have proven to be a suitable technique to give enough information to elucidate the way of bonding of the ligands to the metal ions. The IR spectra of the complexes [Cd(DAP)(Meth)] and [Cd(DAP)(Gly)] (Table 2) show a broad absorption bands at 3367 and $3425 \mathrm{~cm}^{-1}$ attributed to the amino group [38] . The bands assigned to $\mathrm{NH}_{2}$ stretching vibration of the free ligand in the range 3400-3500 $\mathrm{cm}^{-1}$ are shifted to lower frequencies indicating the involvement of the amino group of the ligand into complex formation. The bands appearing in the $2958-2600 \mathrm{~cm}^{-1}$ region (medium to weak) can be assigned to $\mathrm{C}-\mathrm{H}$ stretching vibrations in both the primary and secondary ligands. Low frequency bands corresponding to the vibration of the $\mathrm{Cd}-\mathrm{O}$ and $\mathrm{Cd}-\mathrm{N}$ bands have also been assigned for the complexes. The Cd-O bands appear at 442 and $450 \mathrm{~cm}^{-1}$ whereas, the Cd-N bands appear at 530 and $580 \mathrm{~cm}^{-1}$ for two complexes respectively, which further confirm the formation of the complexes. Bands in the range $1654-1610 \mathrm{~cm}^{-1}$ region are typical of coordinated carboxylate stretching [39]. This assignment is based on the fact that [39] the unionized and uncoordinated $\mathrm{COO}^{-}$stretching band occurs at $1750-1700 \mathrm{~cm}^{-1}$ whereas the ionized and coordinated COO- stretching band appears at $1650-1590 \mathrm{~cm}^{-1}$. This indicates the participation of carboxylate group in the complex formation. The carboxylate stretching bands $v_{\text {as }}$ appear at $1660.5 \mathrm{~cm}^{-1}$ for the methionine complex and at $1642.6 \mathrm{~cm}^{-1}$ for the glycine complex. The $v_{\mathrm{s}}$ appears as a strong band at 1310.5 and at 1391.3 for the methionine and glycine complexes respectively. This also may be taken as evidence, supporting the potentiometric measurements which indicate that methionine is coordinating to DAP as substituted glycinate; i.e. through amino and carboxylate group.

\subsection{Biological activity}

Special interests are now directed to the involvement of metal complexes in medical treatment [40]. All of the tested complexes show a remarkable biological activity against Grampositive $(\mathrm{G}+)$ and Gram-negative $\left(\mathrm{G}^{-}\right)$bacteria, and also fungi. 
Table 3. The antibacterial and antifungal activity of the synthesized metal complexes.

\begin{tabular}{ll|lll}
\hline & \multicolumn{2}{l}{ Inhibition zone diameter $(\mathbf{m m} / \mathbf{m g}$ sample) } & Aspergillus flavus \\
\cline { 2 - 5 } & Escherichia coli $(\mathbf{G}-)$ & Staphylococcus aureus $(\mathbf{G}+)$ & 15 & Candida albicans \\
\hline [Cd(DAP)-Meth]Cl & 15 & 17 & 14 & 17 \\
[Cd(DAP)-Gly]Cl & 17 & 20 & - & 16 \\
Tetracycline & 30 & 28 & 17 & 18 \\
Amphotericine B & - & - & - \\
\hline
\end{tabular}

Table 4. Solvent effect on the dissociation constant of DAP and the formation constant of the Cd-DAP complexes at $25^{\circ} \mathrm{C}$.

\begin{tabular}{|c|c|c|c|c|c|c|}
\hline \% Dioxane (v:v) & System & 1 & p & $q^{a}$ & $\log \beta^{b}$ & $S^{c}$ \\
\hline \multirow[t]{4}{*}{$12.5 \%$} & DAP & 0 & 1 & 1 & $6.93(0.03)$ & $2.91 \times 10^{-6}$ \\
\hline & & 0 & 1 & 2 & $9.92(0.02)$ & \\
\hline & $\overline{\text { Cd-DAP }}$ & 1 & 1 & 0 & $6.76(0.01)$ & $5.62 \times 10^{-7}$ \\
\hline & & 1 & 2 & 0 & $11.98(0.02)$ & \\
\hline \multirow[t]{4}{*}{$25.0 \%$} & DAP & 0 & $\frac{2}{1}$ & 1 & $7.12(0.01)$ & $4.50 \times 10^{-6}$ \\
\hline & & 0 & 1 & 2 & $10.11(0.02)$ & \\
\hline & $\overline{\mathrm{Cd}-\mathrm{DAP}}$ & 1 & 1 & 0 & $6.96(0.01)$ & $3.27 \times 10^{-7}$ \\
\hline & & 1 & 2 & 0 & $12.21(0.02)$ & \\
\hline \multirow[t]{4}{*}{$37.5 \%$} & DAP & 0 & 1 & 1 & 7. $34(0.03)$ & $5.41 \times 10^{-7}$ \\
\hline & & 0 & 1 & 2 & $10.42(0.02)$ & \\
\hline & $\overline{\text { Cd-DAP }}$ & 1 & 1 & 0 & $7.16(0.01)$ & $4.29 \times 10^{-6}$ \\
\hline & & 1 & 2 & 0 & $12.48(0.02)$ & \\
\hline \multirow[t]{4}{*}{$50.0 \%$} & DAP & 0 & 1 & 1 & $7.83(0.03)$ & $4.37 \times 10^{-7}$ \\
\hline & & 0 & 1 & 2 & $10.72(0.05)$ & \\
\hline & $\overline{\text { Cd-DAP }}$ & 1 & 1 & 0 & $7.56(0.01)$ & $4.28 \times 10^{-7}$ \\
\hline & & 1 & 2 & 0 & $12.78(0.02)$ & \\
\hline \multirow[t]{4}{*}{$62.5 \%$} & DAP & 0 & 1 & 1 & 7. $98(0.01)$ & $1.82 \times 10^{-7}$ \\
\hline & & 0 & 1 & 2 & $11.12(0.02)$ & \\
\hline & $\overline{\text { Cd-DAP }}$ & 1 & 1 & 0 & $7.96(0.04)$ & $6.43 \times 10^{-7}$ \\
\hline & & 1 & 2 & 0 & $13.18(0.04)$ & \\
\hline
\end{tabular}

a $l, p$ and $q$ are the stoichiometric coefficient corresponding to $\mathrm{Cd}(\mathrm{II}), \mathrm{DAP}$ and $\mathrm{H}^{+}$, respectively.

b Standard deviations are given in parentheses.

c Sum of squares of residuals.

The data are listed in Table 3. The results obtained show the following:

(a) Using Escherichia coli (G-) and Staphylococcus aureus $(\mathrm{G}+)$ : the biological activity of the glycine complex is higher than that of methionine.

(b) The two solid complexes exhibit higher reactivity against Gram- positive bacteria more than Gramnegative ones. It may be concluded that the antibacterial activity of the compounds is related to cell wall structure of the bacteria. This is possible because the cell wall is essential to the survival of bacteria and some antibiotics are able to kill bacteria by inhibiting a step in the synthesis of peptidoglycan. Gram-positive bacteria possess a thick cell wall containing many layers of peptidoglycan and teichoic acids, but in contrast, Gram-negative bacteria have a relatively thin cell wall consisting of a few layers of peptidoglycan surrounded by a second lipid membrane containing lipopolysaccharides and lipoproteins. These differences in cell wall structure can produce differences in antibacterial susceptibility and some antibiotics can kill only Gram-positive bacteria and are ineffective against Gram-negative pathogens [41].

(c) Using Aspergillus flavus and Candida albicans fungi: the antifungal activity of the methionine complex is higher than that of glycine and close to that of the standard Amphotricin B antifungul agent.

The importance of this lies in the fact that these complexes could be applied fairly in the treatment of some common diseases caused by E. coli, e.g. septicaemia, gastroenteritis, urinary tract infections and hospital acquired infections [42] or any other infections caused by any of these particular strains.

\subsection{Effect of solvent}

Mostly, the physical constants of bioligands are studied in aqueous media. Despite this, little is known about the chemistry of biomolecules in mixtures of organic solvents and water. Determination of the protonation constants bioactive ligands and the stability constants of their metal complexes in various media are important for complete understanding of the physicochemical behavior of such molecules. It is well established that the "effective" or "equivalent solution" dielectric constants in protein $[42,43]$ or active site cavities of enzymes [42] are small compared to that in bulk water. Estimates for the dielectric constant in such locations range from 30 to $70[44,44]$. Hence by using aqueous solutions containing $\sim 10-50 \%$ dioxane, one may expect to simulate to some degree the situation in active site cavities [45]. This allows extrapolating the data into physiological conditions. The solvent effect on the acid dissociation constants of a ligand can be summarized as follows.

(i) As the solvent dielectric constant decreases, the $\mathrm{p} K_{\text {a }}$ of the ligand increases and vice versa.

(ii) On decreasing the extent of hydrogen bonding in water by an organic solvent, the proton-accepting properties of the water increases, and consequently the $\mathrm{pk}_{\mathrm{a}}$ of the ligand decreases.

(iii) Increasing proton salvation by an organic solvent is accompanied by decrease in the $\mathrm{pK}_{\mathrm{a}}$ of ligand.

Careful examination of media effects on the equilibrium constants (Table 4) reveals the following features:

(1) $\mathrm{p} K_{\mathrm{a}}$ of DAP increases linearly with increasing percentage of organic solvent in the medium, Figure 5 . This may be correlated with the ability of a solvent of relatively low dielectric constant to increase the electrostatic forces between the proton and the ligand and consequently the $\mathrm{p} K_{\mathrm{a}}$ value increases.

(2) The stability constant $\left(\log _{10} K_{1}\right)$ of the Cd(II)-DAP complex increases with increase of dioxane concentration, Figure 5. This can be interpreted in terms of an electrostatic model. In general, lowering of the dielectric constant of a medium (by increasing dioxane content) favors the interaction between the Cd(II) ion and DAP and consequently the stability constant of the complex increases. 


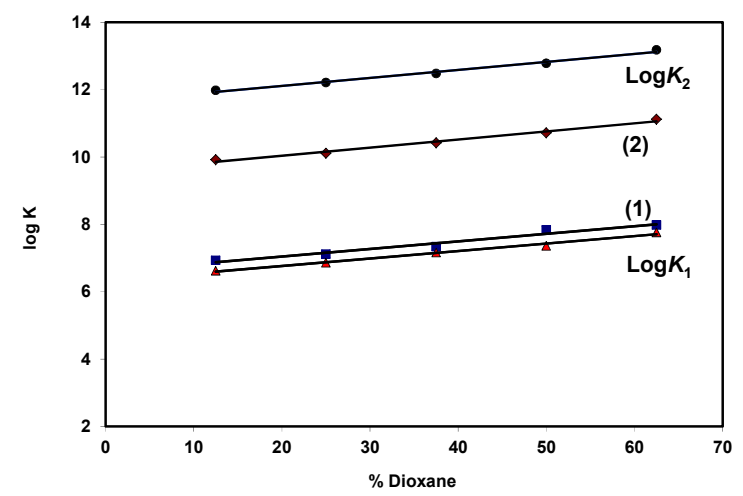

Figure 5. Effect of dioxane on the protonation constant of DAP and the formation constants of Cd-DAP Complexes. Curves: (1) and (2) correspond to the dissociation of DAP ligand. $\log _{10} \mathrm{~K}_{1}$ corresponds to 110 species and $\log _{10} K_{2}$ corresponds to 120 species.

\section{Conclusion}

The present investigation describes the solution equilibria of Cd(II) complexes involving 2,6-diaminopyridine and some selected biorelevant ligands. This study is concerned with the manipulation of the coordination environment of toxic metal ions in order to accelerate their excretion from the organisms. The relatively high stability of the $\mathrm{Cd}(\mathrm{DAP})^{2+}$ complex may encourage the use of DAP as an antidote to release Cd(II). The results showed the formation of Cd(DAP)(L) complexes with amino acids and dicarboxylic acids. The stability constant values obtained for the sulfur donor ligands, methionine and serine, indicate that the thioether group in methionine and $\beta$ alcoholato-group in serine do not participate in complex formation as reported previously $[11,30,31]$ This is also supported by the results of IR spectroscopy of the Cd(DAP)methionine complex, which indicate the involvement of the carboxylate group of methionine in complex formation. The present study shows clearly that deprotonation of the peptide bond was promoted under complex formation. Also, the slight difference in the side chain of the amides has an effect on the induced ionization of the amide proton. The ternary complexes of glycine and methionine were synthesized and characterized and the coordination sites were discussed based on the spectroscopic investigations. The results of the antimicrobial activity show that the complexes exhibit antimicrobial properties. Also, the results indicated that the tested complexes are more active against Gram- positive bacteria than Gramnegative ones. It may be concluded that the antibacterial activity of the compounds is related to cell wall structure of bacteria.

The protonation constants of DAP and the formation constants of Cd(II)-DAP complexes were studied in solvent of lower polarity, (water/dioxane mixtures), taken as an example of some biochemical micro-environments. The results clearly indicate that the formation of the Cd(II)-DAP complex will be more favored in biological environments of low dielectric constant.

It is hoped that the obtained data will be a significant contribution to workers carrying out mechanistic studies in biological media

\section{Acknowledgements}

The authors gratefully acknowledge the Microanalytical Center and the Bacteriology Laboratory of the Faculty of Science, Cairo University, Egypt.

\section{References}

[1]. Shoukry, A. A.; Shoukry, M. M. Annali di Chimica 2007, 97, 733-744.

[2]. Briggs, B. R. L. Bulln. Eniviron. Contam. Toxicol. 1979, 22, 838-845.
[3]. Sugwara, C.; Sugwara, N.; Bulln. Eniviron. Contam. Toxicol. 1975, 14, $159-162$.

[4]. Dressing, S. A.; Maas, R. P. Bulln. Eniviron. Contam. Toxicol. 1982, 28, $172-180$.

[5]. Titus, J. A.; Pfister, R. M. Bulln. Eniviron. Contam. Toxicol. 1982, 28, 697-703.

[6]. Hung, Y. -W. Bulln. Eniviron. Contam. Toxicol. 1982, 28, 546-551.

[7]. Margoshes, M.; Vallee, B. L. J. Am. Chem. Soc. 1957, 79, 4813-4814.

[8]. Kagi, J. H. R.; Valle, B. L. J. Biol. Chem. 1961, 236, 2433-2441.

[9]. Byerrum, R. U.; Anwar, R. A.; Hoppert, C. A. J. Am. Water Work Assoc. 1960, 52, 651-657.

[10]. Rabenestein, D. L.; Isab, A. A.; Kadima, W.; Mohanakrishnan, P. Biochim. Biophys. Acta. 1983, 762, 531-541.

[11]. Shoukry, M. M.; Shehata, M. R.; Mohamed, M. M. Microchim. Acta, 1998, 129, 107-113.

[12]. Shoukry, A. A. J. Solut. Chem. 2011, 40, 1796-1818.

[13]. Shoukry, A. A.; Hosney W. M. Cent. Eur. J. Chem. 2012, 10(1), 59-70.

[14]. Shoukry, A. A.; Shoukry, M. M. Hafez, M. N. Cent. Eur. J. Chem. 2010, 8(4), 797-805.

[15]. Shoukry, M. M.; Shoukry, A. A.; Hafez, M. N. J. Coord. Chem. 2010, 63, 652-664.

[16]. Shoukry, M. M.; Shoukry, A. A.; Khalaf, P. A. A.; Hassan, S. S. Int. J. Chem. Kinet. 2010, 42(10), 608-618.

[17]. Shoukry, A. A.; Brindell, A. A.; Eldik, V. R. Dalton. Trans. 2007, 41694174 .

[18]. Shoukry, A. A.; Mohamed, M. M.; Shoukry, M. M. J. Solut. Chem. 2006, 35, 853- 856 .

[19]. Shoukry, A. A. Trans. Met. Chem. 2005, 30, 814-827.

[20]. Grayer, R. J.; Harbone, J. B. Phytochemistry 1994, 37, 19-42

[21]. El-Sherif, A. J. Solut. Chem. 2010, 39, 1562-1581.

[22]. Stark, J. G.; Wallac, E. H. G.; Chemistry Data Book, (eds.), 75. Murray, London, 1975.

[23]. Van Uitert, G. L; Hass, C. G. J. Am. Chem. Soc. 1971, 75, 451-455

[24]. Motekaitis, R. J.; Martell, A. E.; Nelson D. A. Inorg. Chem. 1984, 23, 275283.

[25]. Serjeant, E. P. Potentiometry and Potentiometric Titrations., Wiley, New York, 1984.

[26]. Jameson. R. F.; Wilson. M. F, J. Chem. Soc. Dalton Trans. 1972, 23 2610-2614.

[27]. Hay, R. W.; Morris, P. J.; Sige, l. H. Metal Ions in Biological Systems. pp. 73. Dekker, New York, 1976.

[28]. Gans, P.; Sabatini, A.; Vacca, A. J. Inorg. Chim. Acta 1976, 18, 237-239.

[29]. Pettit, L. D. SPECIES, available program supplied to the authors, Academic Software, Old Farm, Timbly, Otley, 1993 York, LS21 2PW, UK

[30]. El-Sherif, A. J. Coord. Chem. 2011, 64(7), 1240-1253.

[31]. Pettit, L.; Swash, J. J. Chem. Soc. Dalton Trans. 1976, 2416-2419.

[32]. Kozlowki, H.; Becock, B. R.; Delarulle, J. L.; Loucleux, C. Ancian B. Inorg Chim. Acta 1983, 78, 31-35.

[33]. Savago, I.; Kiss, A.; Farkas, A.; Sanna, D.; Marras P.; Micerain, G. J. Inorg. Biochem. 1997, 65, 103-108.

[34]. Daniele, P. G.; Zerbinati, O.; Zelano, V.; Ostacoli, G. Dalton Trans. 1991 2711-2715.

[35]. Lim, M. C. J. Inorg. Nucl. Chem. 1981, 43, 221-223.

[36]. Maskos, K. Acta Biochem. Pol. 1981, 28, 317-335.

[37]. Maskos, K. J. Inorg. Biochem. 1985, 25, 1-14.

[38]. Snell, F. D.; Hilton, C. L. Encyclopaedia of Industrial Chemical Analysis, 4, 74 Interscience, New York, 1967.

[39]. Nakamoto, K. Infrared and Raman Spectra of Inorganic and coordination compounds, 3rd edn., 311 Wiley, New York, 1978.

[40]. Anacona, J. R.; Lopez, M. Int J. Inorg. Chem. 2012, 106187-106195.

[41]. Jawetz, E.; Melnick, J. I.; Adelberg, E. A. Review of Medical Microbiology, $16^{\text {th }}$ edn., LangMedical, Los Angeles, 1979.

[42]. El-Sherif, A. J. Solut. Chem. 2012, 41, 392-409.

[43]. El-Sherif, A. J. Solut. Chem. 2010, 39, 131-150.

[44]. El-Sherif, A. J. Cood. Chem. 2011, 4, 1240-1253.

[45]. Akerlof, G.; Short, O. A. J. Am. Chem. Soc. 1953, 75, 6357-6357. 